\title{
Improvement of Studying Satisfaction Using a FB-Based e- Learning Interaction Module
}

\author{
Ping-Shu Kuo ${ }^{1}$, Shiow-Lin $\mathrm{Hwu}^{2 *}$, Chih-Min $\mathrm{Lo}^{3}$ \\ 1 Department of Digital Media Design, Hwa Hsia University of Technology. \\ 2 Department of General Education Center, Ling Tung University. \\ ${ }^{3}$ Department of Digital Multimedia Design, National Taipei University of Business. \\ * Corresponding author. Email: slinghu@gmail.com \\ Manuscript submitted December 17, 2014; accepted February 13, 2015. \\ doi: $10.17706 /$ jcp.10.2.138-146
}

\begin{abstract}
Studying satisfaction is one of the main goals in education business no mater in traditional learning environment or in the digital environment. The Social networking service, called SNS, offers a simple way to build social networks among a set of people who share interests, activities, backgrounds or life discussions. Until now, many well-popular SNS tool are easy to use for people no matter the one familiarizes with computer using or not. For example, Facebook (FB) is a common SNS application and owns enormous active users who daily login the platform long time. This program is institutive, convenient, user-friendly, excellent and easy to get into the swing of it. Motivated from this phenomenon, in this paper, we have developed a FBbased module and embed it into an e-learning platform which is a system facilitates whole learners and instructors performing learning activities from each other without the restriction of time and place. To show the contribution, an experiment including organizing participants, data collection, and data analysis is performed to highlight that the studying satisfaction in the experiment group is better than in the control group.
\end{abstract}

Key words: E-Learning, social networking service (SNS), facebook, digital learning platforms, interaction teaching.

\section{Introduction}

To improve studying satisfaction, the achievement of well-interaction among whole participants is not a choice, but a necessity. Until now, many researches conclude that the wisdom exists not only at the individual level, but also is acquired through well interactions among participants ([1]-[5]). Moreover, how the interactions can be significantly increased is also an important consideration, whether being considered in the traditional learning environments or in the digital learning platforms ([6]-[8]).

In article [9], the authors present that e-learning is a complex process when participating and maintaining relations for each other. Since the activities of e-learning are carried out on the go, without face-to-face discussions [10], the participant's interaction is very limited in the kinds of platform. The interaction is undoubtedly crucial for the learning objective and learning satisfaction. It is necessary to successfully guide the participants to achieve the appropriate interaction to ensure the learning objective, thus accomplishing the learning satisfaction.

Generally speaking, several parties including learner, instructor, and content, are involved in an e-learning system ([11], [12]). While the interactions among these parties are well-defined and kept, the learning objective can be thus arrived at. However, the possible interactions are complicated and are difficult to be 
distinguished since the scope is comprehensive. The learning satisfaction depends on the provision that the interaction among participants is formatted. For instance, the interaction between two learners should be publicly performed following a formal method to prevent any meaningless chatting. A practical solution, which models the interaction processes, is reasonably useful to overcome the issue. That is the basis to share the advantages provided by the interaction among participants and the online learning system. To construct the solution, a design which developed the interactions process with a systemic construction is preferred. Unfortunately, to our knowledge, the previous approaches ([13], [14]) concerning of the aspect of interaction and learner participation lack the presence.

The user interfaces of discussion and interact on which provided in a traditional e-learning system is usually not friendly designed. When a learner joining the platform for studying some course, the first work he has to do is to know how to discuss with other participants. It is not a simple task since the function is not the same for every different platform. In other words, if the interface given nears to some function that the mot learners have already knew how to use it; the promotion of interaction may be easier.

The social networking service which is called SNS becomes more and more popular and provides a simple way to build social networks among people who wish share interests, activities, backgrounds or life discussions. Nowadays, many well-established SNS tool are developed, such as Facebook (FB), which are easy to use for people in all ages no matter the one familiarizes with using computer or not. Facebook has become one of the most popular social networking sites and owns enormous active users the entire world (864 million daily active users on average for September ([15]), and those users daily login the platform long time. The application is very helpful to maintain the relationships with others when the users are not active online and becomes a genuine guideline of communication since most students from high school to university use it to keep in touch with their friends almost every day.

In this paper, we develop a FB-based interaction module and embed it in an e-learning platform for interaction improvement. The major idea is motived from the phenomenon that the Facebook software is very institutive, convenient, excellent, user-friendly and easy to get into the swing of it. Then, in order to show the contribution of our methodology, an experiment is designed and assessed to compare the users' studying satisfaction between the experiment group and the control group. In this experiment, we arrange 122 students between sixteen and nineteen years of age from a Taiwanese private College of Technology with the experimental course, Information Literacy. The major goal of this experiment is to make sure that the studying satisfaction in the experiment group using the FB module is better than the control group using a traditional e-learning interaction module.

The rest of this paper is organized as follows. Section 2 briefly describes related works to facilitate the understanding of the article. In Section 3, the method with FB-based interaction module is presented and a experiment is developed so that the learners can discuss the teaching content more friendly and easily. Then, the experiment and discussion are opened to demonstrate the main contribution of the proposed method in Section 4. Finally, the conclusion is given in Section 5.

\section{Related Works}

\subsection{Participants' Interaction Concerns in e-Learning Platform}

Hrastinski's online learner participation theory is proposed [9] derived from the structuralism and social learning theory in educational philosophy. In the structuralism, learning should not be solely a one-way conferral. Instead, it should be pieced together by the learner group because knowledge exists not only in an individual, but also in a whole group. Social learning theory presents that learning is part of human activity in society, where the person's knowledge is derived from interaction with other people ([16]). Due to the corresponding perspectives in online learner participation theory, studies focused on learner participants are essential. Unlike conventional concerns, online learner participation theory [9] states that learning is a 
complex process of interaction and maintenance with others. The teaching process should include a series of engaging motions supporting learner's strengths physically and psychologically. That is, team brainstorming via the discussions with each other in a group is an effective way to obtain knowledge ([3], [4]). Hence, the usage through online learners' interaction helps improve the studying satisfaction in e-learning environments.

Until now, many business e-learning platforms are developed. Those systems offer good communication tools between instructors and learners, such as the discussion board, E-whiteboard, e-mail, instant messages (IM) software and so on. Even though those mechanisms could provide some benefits, those still have the disadvantages regarding insufficient ability to simultaneously present different file formats ([2]), unfamiliarity of operations, and platforms that are not good designed for the purpose of interaction in elearning process. Therefore, an adapted tool facilitates the interaction of whole participates without tough operation is desired.

\subsection{Facebook}

Prior using Facebook, the online registration and creating a profile by using a valid e-mail address are both necessary. The elements of a Facebook profile may be classified into four types: control elements, referents elements, preference elements, and contact elements ([17]), Control elements contain the gender of the user, length of membership in Facebook, and institutional status. Referents elements are related to basic viewpoint of reference among users such as hometown, high school, residence, and concentration. Personal interest and self-descriptive information are expressed in preference elements. Contact elements are with the following: offline mailing address, e-mail address, instant messenger screen name, relationship status, and birthday.

Facebook users can communicate with one another by several ways. He/She can send messages privately to someone else. This is similar to emailing ([18]), except that messages may only be sent to one recipient at a time ([19]). Besides, users can also operating the Wall, which is a space on the profile, somewhat like a notice board or a public forum where users can release messages by interchanging all kinds of multimedia ([20], [21]). Furthermore, by using the chat function, Facebook users can communicate with each other immediately. Instant messaging is a text-based communication tool that permits interaction between two individuals ([22]). There is also the News Feed function which shows some topic the user's friends may interested.

\section{The Methodology}

There are several e-learning platforms implemented for learning and teaching purposes in many universities, high schools, research institutes, and so on. In most platforms, the participants' discussion area always is provided to facilitate processing users' interaction function regarding of any course-related problems. However, the components of discussion area in each platform are not the same since they may be developed by different software teams. The learner has to know how the flow and operation is in the discussion area before using the function. Without proper knowledge of the operations, it is difficult to obtain good interaction with other participants. In Fig. 1, an implemented example of popular discussioninteraction function in a traditional e-learning system is shown.

To enhance learning satisfaction, the interaction function used in Facebook is tied in with the e-learning platform. Gained from the benefits of Facebook, the new method provides a good and institute way to discuss course content with other participants without knowing its operations. In Fig. 2, the new discussioninteraction function derived from Facebook for learners' interaction is shown. The interaction function shown in Fig. 3 demos that the learners are capable of raising problems in terms of teaching course and not only the instructors but also the other learners can be requestors with their experiences. Furthermore, the bulletin function is also provided in the Facebook module as shown in Fig. 4, and all participants can easily 
announce message to others with access control considerations. In a word, the Facebook-base module facilitates establishing of an intuitive-mutual e-learning platform for whole participants.

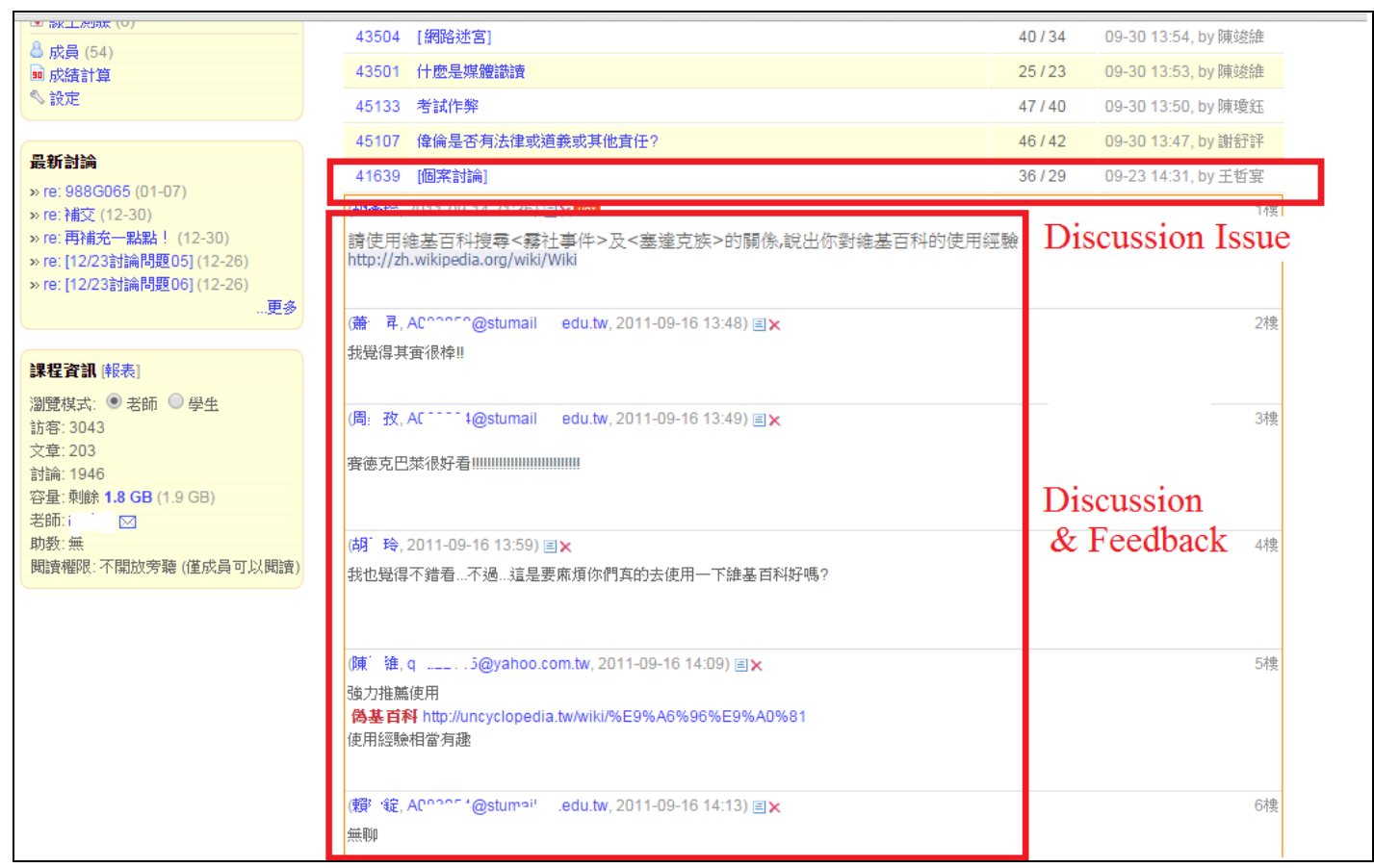

Fig. 1. The popular discussion-interaction functions in a traditional e-learning system.

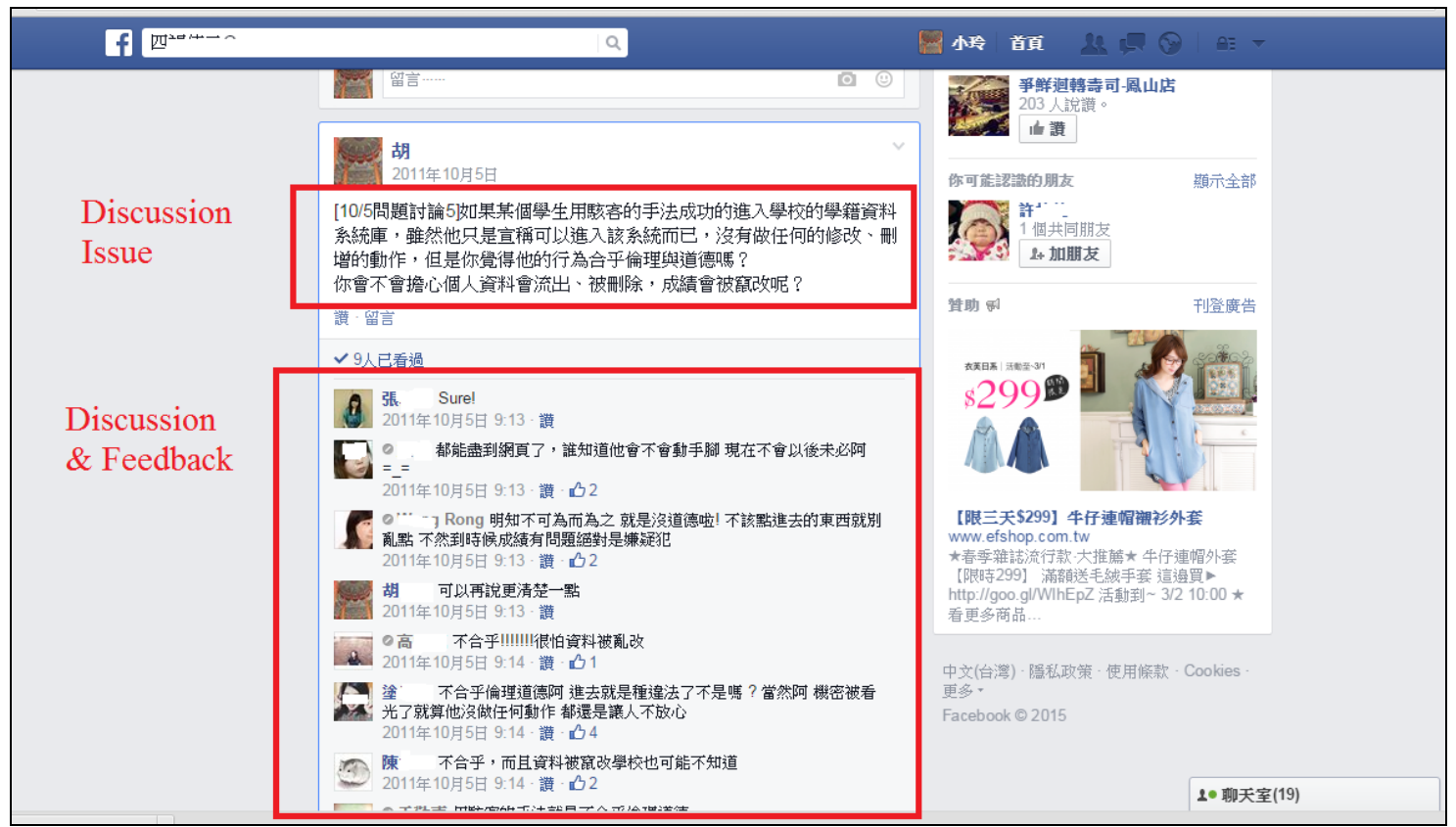

Fig. 2. The discussion-interaction functions in a FB-based module.

In order to validate the contribution of the FB-based methodology presented in paper, an experiment which measures the studying satisfaction based on the platform with the FB-based interaction module is developed. It includes several major parts which are described as follows:

\subsection{Participants}

122 students between sixteen and nineteen years of age are recruited from a Taiwanese private College of Technology with the experimental course, Information Literacy. These students are randomly divided into two group (Group A and B), which is useful for eliminating the differences of learner motivation and 
background. The students in Group A make use of the proposed FB-based module for interaction between each other. Then, Team B is allocated to using a common learning platform with an existing tool. The Fig. 3 is an example of the Group A (FB-based module) user's questions regarding of learning processing as well as the teacher's corresponding answer. It offers an easy and directed way for interaction.

For precise results, the learning programs designed in the experiment eliminate the possible condition, besides the interaction tool. Both groups A and B execute comment feedback partially, and the complete feedback can be received in the final team reporting. The occasion of feedback response is set throughout weeks 2 to 6.

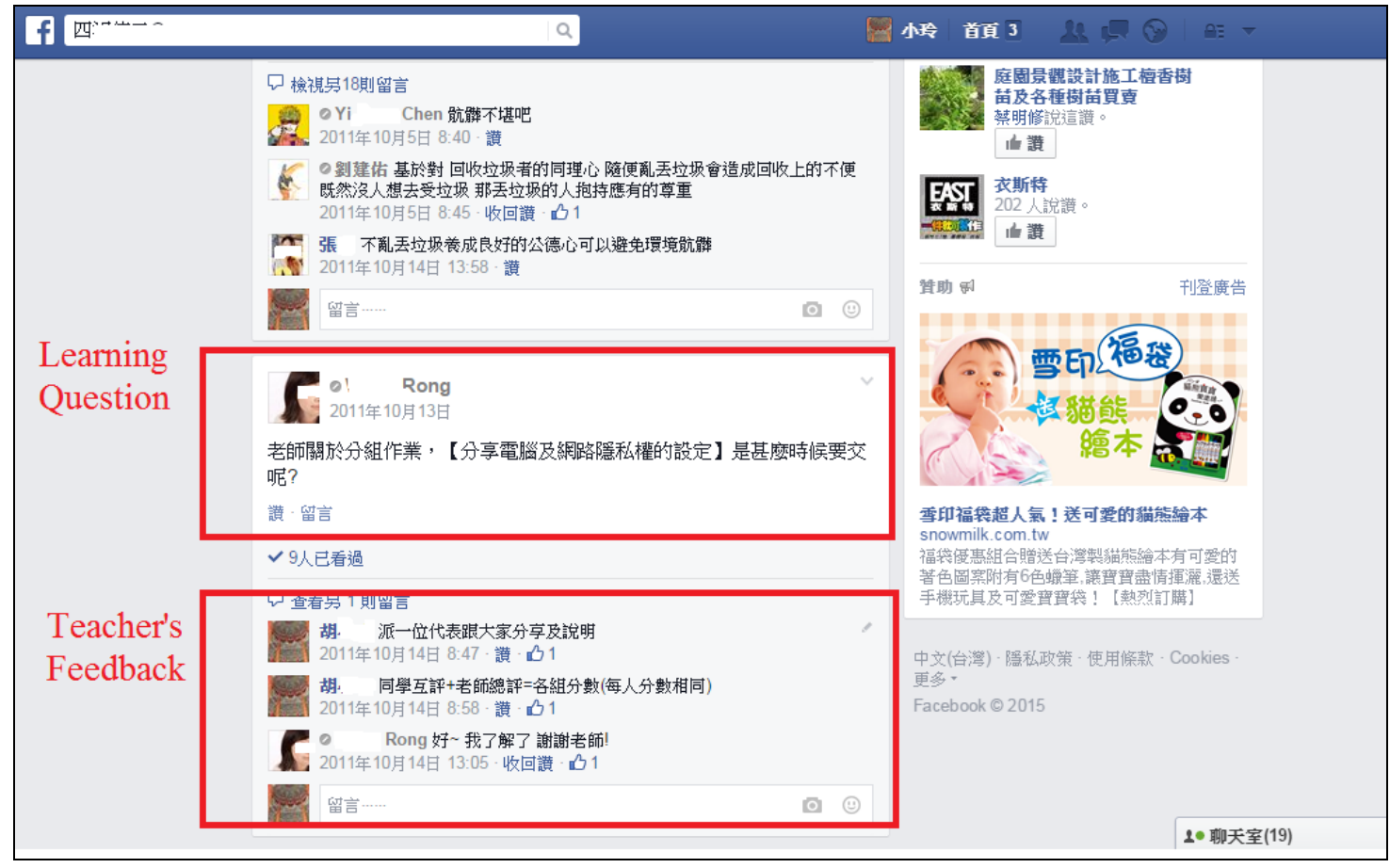

Fig. 3. The discussion-interaction functions in a FB-based module.

\subsection{Data Collection}

This research applies questionnaire survey in order to investigate the comments of users who utilized the two different interaction functions. During teaching process, the two groups receive identical course and content except using the different interaction functions, which makes sure the consistency of their background. There are eleven dimensions involved in the questionnaire based on the possible clue referred from lecture survey. According the pretest result from 41 testers, the reliability is acceptable (Cronbach's alpha value is 0.91 ) and the construct validity is 0.79 , thus guaranteeing the reliability and validity of the questionnaire survey.

From the statistical findings of the survey, we visited some of the participants and a simple interview. Structured interview question contains two main questions. "Overall, I think this course using interactive learning experiences in the past and did not use the Internet compared whether it is more suitable for the teaching of communication and please explain why?", "The whole words, I think the way this course is interactive use of underclassmen who can recommend to use ? Please explain why". Using this kind of open discussion of questions and answers, it is easier to guide the personal experience of respondents.

The way of structured interviews facilitates the questionnaires of collecting and reinforcing missing information. Thus, this study collects data for both qualitative manner and quantitative research methods.

\subsection{Data Analysis}


This experiment applies several means of analysis in order to examine the collected data. The descriptive analysis method and the inferential statistics technique are mean and standard deviation and independentsamples t-test, respectively. These methods are implemented following the basic assumptions. In inferential tests, the experiment uses an alpha level (significance level) of 0.05. In the analysis of data descriptive statistics (number, percentage, arithmetic medium and standard deviation); with the aim of determining difference between dependent and independent variables; and $t$-test for independent groups.

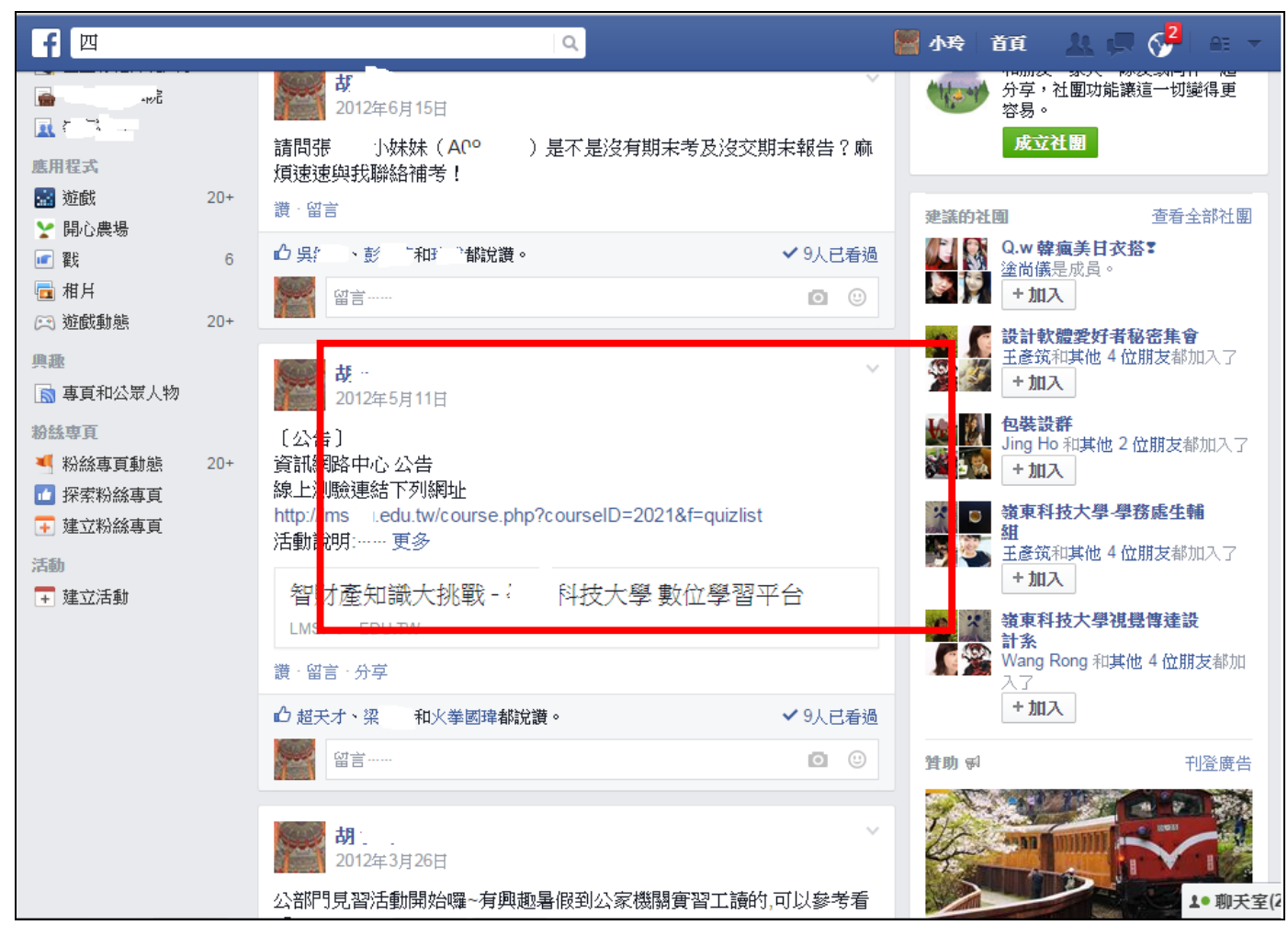

Fig. 4. The bulletin functions in a FB-based module.

\section{Results and Discussions}

The results of experiment are summarized in Table 1. There are four dimensions including "It is helpful for me to highlight learning inexpression", "It is helpful to know other partners soon"," It is helpful to narrow me and other partners", and "It is convenient to discuss course with partners", revealed significant differences between these two groups. Based on the $95 \%$ confidence interval, Groups A and B are with significant differences. On the other hand, compared with the leaners in Group B, the learners in the Group A (who used FB-based interaction module) appear higher studying satisfaction. Therefore, it is clear that the influence of interaction operations between participants is very crucial and is a point to evaluate studying effectiveness during the use of an e-learning platform.

Two concerns derived from the results are discussed as follows. First, although SD of Group B in 2-4 and 29 reveals higher scale than Group A which equipped with FB-based interaction mechanism, it is still not reach significant level. The possible reason can be suspected as that the learners take FB module as a specific platform of interacting with the learning partners rather than interacting with the instructors based on a brief discussion with some members of Group A. Second, the mean of 2-6 and 2-7 only reaches 3.97 and are obviously lower compared to other dimensions. The deeper analysis to express this situation of the awareness of knowing and narrowing among peers should be a new research topic and is out of the scope of this paper. Some survey and the corresponding experiment can be further processed to precisely explore why the mean of 2-6 and 2-7 is not good enough. 
Table 1. Results

\begin{tabular}{|c|c|c|c|c|c|c|}
\hline Dimension & Group & $\overline{\mathrm{N}}$ & Mean & SD & "Std. Error Mean & $\overline{T T}$ \\
\hline \multirow{2}{*}{$\begin{array}{l}2-1 \text {. It is helpful for me to thoroughly } \\
\text { realize course content }\end{array}$} & $\mathrm{A}$ & 60 & 4.22 & 0.524 & 0.068 & \multirow[t]{2}{*}{0.867} \\
\hline & $\mathrm{B}$ & 62 & 4.11 & 0.770 & 0.098 & \\
\hline \multirow{2}{*}{$\begin{array}{l}\text { 2-2. It is helpful for me to highlight } \\
\text { learning inexpression }\end{array}$} & $\mathrm{A}$ & 60 & 4.18 & 0.504 & 0.065 & \multirow[t]{2}{*}{$2.254 *$} \\
\hline & $\mathrm{B}$ & 62 & 3.89 & 0.889 & 0.113 & \\
\hline \multirow[t]{2}{*}{ 2-3. It enlightens my thinking of problems } & A & 60 & 4.13 & 0.596 & 0.077 & \multirow[t]{2}{*}{1.398} \\
\hline & $\mathrm{B}$ & 62 & 3.95 & 0.818 & 0.104 & \\
\hline \multirow{2}{*}{$\begin{array}{l}\text { 2-4. It is convenient to discuss course with } \\
\text { instructor }\end{array}$} & A & 60 & 4.17 & 0.717 & 0.093 & \multirow[t]{2}{*}{-0.072} \\
\hline & $\mathrm{B}$ & 62 & 4.18 & 0.915 & 0.116 & \\
\hline \multirow{2}{*}{$\begin{array}{l}\text { 2-5. It is easy to communication with } \\
\text { instructor }\end{array}$} & $\mathrm{A}$ & 60 & 4.13 & 0.700 & 0.090 & \multirow[t]{2}{*}{0.136} \\
\hline & $\mathrm{B}$ & 62 & 4.11 & 0.943 & 0.120 & \\
\hline \multirow{2}{*}{$\begin{array}{l}\text { 2-6. It is helpful to know other partners } \\
\text { soon }\end{array}$} & $\mathrm{A}$ & 60 & 3.97 & 0.780 & 0.101 & \multirow[t]{2}{*}{$2.860 * *$} \\
\hline & B & 62 & 3.47 & 1.112 & 0.141 & \\
\hline \multirow{2}{*}{$\begin{array}{l}\text { 2-7. It is helpful to narrow me and other } \\
\text { partners }\end{array}$} & $\mathrm{A}$ & 60 & 3.97 & 0.712 & 0.092 & \multirow[t]{2}{*}{$3.312 * *$} \\
\hline & $\mathrm{B}$ & 62 & 3.37 & 1.204 & 0.153 & \\
\hline \multirow{2}{*}{$\begin{array}{l}\text { 2-8. It is convenient to discuss course with } \\
\text { partners }\end{array}$} & $\mathrm{A}$ & 60 & 4.22 & 0.585 & 0.076 & \multirow[t]{2}{*}{$2.524^{*}$} \\
\hline & B & 62 & 3.82 & 1.064 & 0.135 & \\
\hline \multirow{2}{*}{$\begin{array}{l}\text { 2-9. It makes chances of whole partners' } \\
\text { speech }\end{array}$} & A & 60 & 4.32 & 0.596 & 0.077 & \multirow[t]{2}{*}{-0.041} \\
\hline & B & 62 & 4.32 & 0.937 & 0.119 & \\
\hline \multirow{2}{*}{$\begin{array}{l}\text { 2-10. It lets me know the opinions of other } \\
\text { partners }\end{array}$} & $\mathrm{A}$ & 60 & 4.37 & 0.551 & 0.071 & \multirow[t]{2}{*}{0.420} \\
\hline & B & 62 & 4.31 & 0.968 & 0.123 & \\
\hline \multirow{2}{*}{$\begin{array}{l}2-11 . \text { It lets me more interested to this } \\
\text { course }\end{array}$} & $\mathrm{A}$ & 60 & 4.02 & 0.676 & 0.087 & \multirow[t]{2}{*}{1.743} \\
\hline & $\mathrm{B}$ & 62 & 3.74 & 1.023 & 0.130 & \\
\hline
\end{tabular}

${ }^{*} p<.05 ;{ }^{* *} p<.01$

The brief discussion with five learners in Group A is summarized in the following:

Learner 1:

The open discussion of learning question from each other is a good idea to enhance knowledge and get close to partners. In the traditional classroom teaching and learning, most students usually deny to say something publicly because of the shy. By using network, the restriction of shy can be reduced and the talking with each other can be much more easy and fast. Thus, all participants including teachers and students are able to easily hold the opinions and thinking of whole members.

Learner 2:

The e-learning platform with FB-module is good in terms of convenient and availability. There is no affect of place and time. That is, we are able to learn no matter in any time or in any where. I am very like to propose my ideas and questions on the network interface. It also helps me to get some one else's responses soon via this platform and this advantage is excellent to solve my concerns and makes the learning results better.

Leaner 3:

This is a cheerful studying method which improves our learning effectiveness. I recommend this kind of method to further learners since taking use of the Facebook software attracts most students and results in the attention significantly during the teaching processing. Undoubtedly, Facebook is feasible and is interesting to us.

\section{Leaner 4:}

To understand the knowledge course and learn deeply, the tightly combination of e-learning and Facebook is an excellent idea. The well-established network and computer hardware and software let us avoid the restriction of long distance and sound. In such a way, I can easily learn and answer the course problems which are claimed by the instructor. On the other hand, this platform also provides a simple way to get more different opinions for other learners on the platform. Another obvious benefit is that the whole discussion contents of every course are completely recorded, and the contents can be easily and quickly searched by using the mature Facebook module platform even if the time goes by.

Learner 5:

In the traditional classroom environment, the students may lose some important contents during processing 
teaching because the physical distance causes harder viewing and listening. The e-learning environment helps us to clearly see whole content the teachers have shown and can get the participants' response very soon if I have any confuses. The interaction improvement is done by the better Facebook e-learning system rather than the traditional method.

According to the discussion with five learners in Group A, most answerers approve that the Facebookbase module is a suitable learning-teaching tool and is excellent for interaction purpose during teaching processing compared to previous network learning experiences. Moreover, they also recommend the Facebook module e-learning platform as a part of e-learning platform in the future.

\section{Conclusion}

With increasing development of computer and internet technology, e-learning is not only viable but also a tendency in educational business. The interaction among whole participants is one of the crucial factors to achieve studying satisfaction. To simplify the interaction, we have built an FB-based interaction e-learning module through the use of the Facebook application, which is very popular for most people. The major contribution is to evaluate the studying satisfaction between the groups with traditional interaction function and FB-based module, respectively. The experiment, which has eliminated the possible factors of correctness influence, is involved for assessment of the work. According to the result, it is concluded that a simple way is help to achieve appropriate interaction among participants, thus levering the studying satisfaction up.

\section{References}

[1] Beauchamp, G., \& Kennewell, S. (2010). Interactivity in the classroom and its impact on learning. Computer \& Education, 3(54), 759-766.

[2] Hwang, K. A., \& Yang, C. H. (2008). A synchronous distance discussion procedure with reinforcement mechanism: Designed for elementary school students to achieve the attending and responding stages of the affective domain teaching goals within a class period. Computer \& Education, 51, 1538-1552.

[3] Koretsky, M. D., Amatore, D., Barnes, C., \& Kimura, S. (2008). Enhancement of student learning in experimental design using a virtual laboratory. IEEE Transactions on Education, 51, 76-85.

[4] Reilly, R. (2008). Virtual laboratories: Enhancing deep learning in model-based knowledge domains. IEEE Transactions on Education, 51, 69-75.

[5] So, H. J., Seah, L. H., \& Toh-Heng, H. L. (2010). Designing collaborative knowledge building environments accessible to all learners: Impact and design challenges. Computer \& Education, 54, 479-490.

[6] Hakkarainen, K. (2009). Three generations of technology-enhanced learning. British Journal of Educational Technology, 40, 879-888.

[7] Lau, A., \& Tsui, E. (2009). Knowledge management perspective on e-learning effectiveness. KnowledgeBased Systems, 22, 324-325.

[8] Liu, M.-C., \& Wang, J.-Y. (2010). Investigating ,knowledge integration in web-based thematic learning using concept mapping assessment. Educational Technology \& Society, 13(2), 25-39.

[9] Hrastinski, S. (2009). A theory of online learning as online participation. Computers \& Education, 52, 7882.

[10] Benbunan-Fich, H., \& Turoff (2003). Decision Support Systems, 34(4), 457-469.

[11] Chou, C., Penga, H., \& Changa, C.-Y. (2010). The technical framework of interactive functions for coursemanagement systems: Students' perceptions, uses, and evaluations. Computer \& Education, 3(55), 10041017.

[12] Jou, M., Chuang, C.-P., \& Wu, Y.-S. (2010). Creating Interactive Web-based environments to scaffold creative reasoning and meaningful learning: from physics to products. The Turkish Online Journal of Educational Technology, 4(9), 49-57. 
[13] Gaetaa, M., Orciuoli, F., \& Ritrovatoa, P. (2009). Advanced ontology management system for personalised e-Learning. Knowledge-Based Systems, 4(22), 292-301.

[14] Sherry A. C., \& Yamashita, S. F. (2004). Selected strategies for interaction in web-based courses. Distance Learning, 4(1), 1-6.

[15] Facebook Offical Website. (December, 2014). Company Information. From http://newsroom.fb.com/company-info/

[16] Wenger, E. (1998). Communities of Practice: Learning, Meaning, and Identity. NY: Cambridge University Press.

[17] Ellison, N. B., Steinfield, C., \& Lampe, C. (2007). The benefits of facebook "friends:" Social capital and college students' use of online social network sites. Journal of Computer-Mediated Communication, 12(4), 1143-1168.

[18] Pempek, T. A., Yermolayeva, Y. A., \& Calvert, S. (2009). College students' social networking experiences on facebook. Journal of Applied Developmental Psychology, 30(3), 227-238.

[19] Golder, S. A., Wilkinson, D., \& Huberman, B. A. (2007). Rhythms of social interaction: Messaging within a massive online network. Proceedings of the Third Communities and Technologies Conference (pp. 41-66).

[20] Ross, C., Orr, E. S., Sisic, M., Arseneault, J. M., Simmering, M. G., \& Orr, R. R. (2009). Personality and motivations associated with facebook use. Computers in Human Behavior, 25(2), 578-586.

[21] West, A., Lewis, J., \& Currie, P. (2009). Students' facebook 'Friends': Public and private spheres. Journal of Youth Studies, 12(6), 615-627.

[22] Nardi, B. A., Whittaker, S., \& Bradner, E. (2000). Interaction and outeraction: Instant messaging in action. Proceedings of the 2000 ACM Conference on Computer Supported Cooperative Work (pp. 79-88).

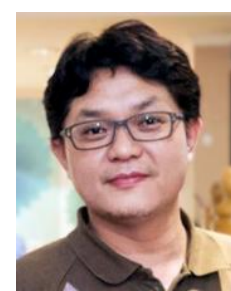

animation.

Ping-Shu Kuo was born in Taipei, Taiwan, R.O.C., in 1968. He received the B.S. degree in oceanography from National Taiwan Ocean University, Keelung, Taiwan, R.O.C., in 1992, and the M.F.A. degree in computer arts from Academy of Art University, San Francisco, in 2002.

$\mathrm{He}$ is currently a lecturer with the Department of Digital Media Design, Hwa Hsia University of Technology, New Taipei City, Taiwan, R.O.C. His current research interests include computer graphics, image-based rendering, skeletonization, and computer

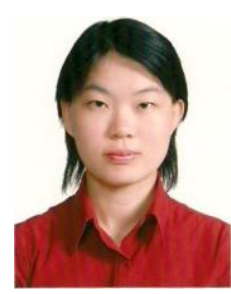

Shiow-Lin Hwu received the B.S. degree from the Department of Information management, Chaoyang University of Technology, Taichung, Taiwan, in 2000. She received the M.S. degree and Ph.D. degree from the Department of Industrial Education and Technology, National Changhua University of Education, Changhua, Taiwan, in 2002 and 2011, respectively. Dr. Hwu's current research interests include learning theory and pathway, e-learning behavioral pattern, e-learning system development, and instructional knowledge management.

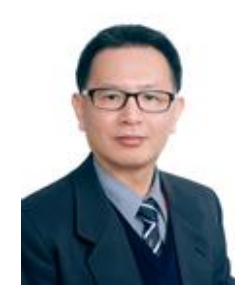

Chih-Min Lo received his master degree in information management in 1996 from National Central University, Taoyuan, Taiwan, and the Ph.D. degree from National Taiwan University of Science and Technology, Taipei, Taiwan, in 2012. He is currently an assistant professor in the Department of Digital Multimedia Design, National Taipei University of Business, Taiwan. His main research interests include software engineering, object-oriented technology, database management system, software information system development, and digital game design. 